\title{
LO NEOFANTÁSTICO EN AURA, DE CARLOS FUENTES: DIMENSIONES ESPACIALES Y TEMPORALES EN LA CONSTRUCCIÓN NARRATIVA
}

\section{ELIOMAR RODRIGUES MAIA*}

Universidade Estadual de Mato Grosso do Sul (Uems), Programa de Pós-Graduação Stricto Sensu em Letras, Campo Grande, MS, Brasil.

Recebido em: 10 fev. 2021. Aprovado em: 4 mar. 2021.

Como citar este artigo: MAIA, E. R. Lo neofantástico en Aura, de Carlos Fuentes: dimensiones espaciales y temporales en la construcción narrativa. Cadernos de Pós-Graduação em Letras, v. 21, n. 1, p. 98-110, jan./abr. 2021. doi: 10.5935/cadernosletras.v21n1p98-110

\section{Resumen}

El presente trabajo trata de hacer un análisis de la narrativa en Aura, de Carlos Fuentes, bajo la perspectiva de lo neofantástico, según el crítico argentino Jaime Alazraki. Se prioriza las dimensiones de tiempo y espacio como elementos de caracterización de esa modalidad literaria. Inicialmente, se traza un breve panorama del contexto de surgimiento de lo neofantástico, bajo la óptica del crítico Rámon Xirau.

* E-mail: feixedepalavras@hotmail.com 


\section{Palabras clave}

Neofantástico. Tiempo. Espacio.

"Queima lentamente

Embebido em seiva quente

0 pavio da vida."

(o autor) ${ }^{1}$

\section{INTRODUCCIÓN}

Históricamente el pensamiento humano ha se modificado o ha sido forzado a cambiar de rumbo bajo la irrupción de nuevas ideologías. Si en el campo social y político el resultado de esas transformaciones se tradujo en revoluciones o conflictos, en el terreno de la literatura no ha sido muy diferente. Aunque la espada y la pólvora literarias no tengan, de forma directa, atentado contra la vida, es cierto, que las ideas contenidas en obras, manifiestos y tratados pusieron en duda el concepto de la propia realidad y de lo racional, decapitando y lanzando por los aires concepciones vigentes.

En el siglo XVIII, La enciclopedia, de Diderot y d'Alembert, inaugura uno de esos marcos históricos que van a influenciar y modificar - a través del pensamiento filosófico - el propio modo de pensar y ver el mundo. La valoración del hombre y de la razón en oposición a la fe religiosa se constituye como base del movimiento iluminista para dar explicación al mundo.

Es en oposición a esa tiranía de la razón, en que todo podía ser explicado por las leyes de la naturaleza, ya en el siglo siguiente, con las obras de Hoffman, Irving, Balzac, Hawthorne, entre otros, que ha florecido la literatura fantástica. ¿Su propósito? Contestar la hegemonía de lo racional, haciendo surgir, lo inexplicable, lo sobrenatural, en resumen, lo irracional. Poner de manifiesto la relativa validez del conocimiento racional, iluminar una zona de lo humano donde la razón está condenada a fracasar. Definir esta modalidad literaria llamada de "género fantástico" o simplemente "fantástico" no se constituye tarea

1 O haicai constava num outro material enviado à essa Instituição, intitulado " $A$ caçada”, de Lygia F. Telles: um conto exemplar de teor e estética fantásticos”, o qual saiu da lista de publicação para dar lugar ao presente trabalho. 
sencilla. Como apunta David Roas (2001, p. 7), en su artículo “La amenaza de lo fantástico":

[...] contamos con una gran variedad de definiciones que, tomadas en su conjunto, han servido para iluminar un buen número de aspectos del género fantástico; aunque también es cierto que muchas de estas visiones son excluyentes entre sí, al limitarse a aplicar los principios y métodos de una determinada corriente crítica. Es por esto que todavía no contamos con una definición que considere en conjunto las múltiples facetas de eso que hemos dado en llamar literatura fantástica.

Sin embargo, hay importantes estudios dedicados a explicar lo fantástico. Elegir uno u otro como el más exacto puede no acercarse a lo razonable, remendar los recortes en un tejido de interpretación único parece ser mucho más conveniente. Aunque no se pueda alejar por completo de la forma tradicional de lo fantástico, en este artículo, todavía, no vamos a poner los estudios del género en evidencia, pues nuestra atención se vuelve para su derivación, lo neofantástico. Así, se busca presentar el contexto de surgimiento y características de esta variación tomando como base el estudio del crítico argentino Jaime Alazraki (1934-2014). A continuación, se analiza, bajo la perspectiva neofantástica, los aspectos espaciales y temporales de la novela Aura, del escritor mexicano Carlos Fuentes.

\section{LA CRISIS DEL REALISMIO, ORIGEN DE LO NEOFANTÁSTICO Y SUS RASGOS DEFINIDORES}

El filósofo mexicano Ramón Xirau (1997) en su artículo "Crisis del realismo" plantea algunas indagaciones con respecto a la crisis del realismo en Latinoamérica. El autor investiga y cuestiona si hubo, de forma efectiva, un cambio brusco en el curso creativo de las letras en Latinoamérica, o si esa mudanza de rumbos puede ser entendida desde la perspectiva de una renovación.

Apunta Xirau (1997) que dentro las letras hispánicas de la era clásica ( $E l$ Cid, por ejemplo), en la literatura real y de bulto ya aparecía en muchas ocasiones una suerte de voluntad de violar la realidad y trascenderla. A partir del siglo XIX, apartado del realismo de las encarnaciones, de tradición cristiana, nace en Latinoamérica, procedente de Francia, otro tipo de realismo; un realis- 
mo que se funda, precisamente, en los hechos. Este tipo de realismo suele ser de origen social y psicológico para convertirse a veces en análisis de costumbres y en costumbrismo, afirma Xirau (1997).

El filósofo señala que esa tradición realista, sobre todo en Latinoamérica, tuvo duración relativamente corta. A partir de Martí, de Nájera, de Rubén Darío, el realismo - en plena época realista - entra en crisis.

El movimiento realista, especialmente en la novela, y en menor grado en el teatro, revive en el siglo XX, todavía afirma Xirau (1997) que el realismo no es el movimiento principal en las letras latinoamericanas como tampoco lo es, a partir de los años de 1930. Lo que predomina, a partir de los años 1920 y 1930 es una literatura que busca "otra" realidad sin por ello tener que desentenderse de la realidad en que ha nacido.

Los movimientos de vanguardia surgidos durante los primeros años de la Primera Guerra Mundial repercuten en Latinoamérica hasta matizarse y adquirir orientaciones propias. Xirau (1997) señala que es en este momento que verdaderamente renace la (nuestra) literatura, caracterizada por la búsqueda de la unión de los opuestos en el inconsciente. Dos momentos marcan el surgimiento de esa nueva literatura latinoamericana: el primero simbolizado en la obra de Vicente Huidobro, Pablo Neruda y Jorge Luis Borges; el segundo, principalmente, en las obras de Octavio Paz, Julio Cortázar, Carlos Fuentes, Gabriel García Márquez, Juan Rulfo, Lezama Lima.

Los conflictos y problemas que surgieron con las nuevas fuerzas en juego, a partir del término de la Primera Guerra Mundial, repercutieron en el contexto de las letras latinoamericanas. Ese nuevo modo de hacer literatura puesto en destaque por escritores como Borges y Cortázar ha sido llamado por el crítico Jaime Alazraki de neofantástico.

Partiendo de declaraciones del propio Cortázar que había afirmado que su literatura pertenecía al género fantástico por falta de mejor nombre, Alazraki (2001, p. 276) propone una caracterización/definición de este nuevo género:

Non son intentos que busquen devastar la realidad conjurando lo sobrenatural - como se propuso el género fantástico en el siglo XIX -, sino esfuerzos orientados a intuirla y conocerla más allá de esa fachada racionalmente construida. Para distinguirlos de sus antecesores del siglo pasado propuse la denominación "neofantástico" para este tipo de relatos. Neofantástico porque a pesar de pivotear alrededor de un elemento fantástico, estos relatos se diferencian de sus abuelos del siglo XIX por su visión, intención y su modus operandi. 
Tomando en préstamo una citación de R. Caillois, Alazraki (2001, p. 276), todavía, remata:

Lo neofantástico asume el mundo real como una máscara, como un tapujo que oculta una segunda realidad que es el verdadero destinatario de la narración neofantástica. La primera se propone abrir una "fisura" o "rajadura" en una superficie sólida e inmutable; para la segunda, en cambio, la realidad es -como decía Johnny Carter en "El perseguidor" - una esponja, un queso gruyere, una superficie llena de agujeros como un colador y desde cuyos orificios se podía atisbar, como en un fogonazo, esa otra realidad.

Pero, ¿cómo caracterizar estos nuevos elementos, visión, intención y modus operandi, apuntados por Alazraki dentro de esa nueva narrativa? De manera breve, tratemos de hacer un ejercicio de comprensión y de representación de esos nuevos elementos, característicos de lo neofantástico, en la construcción narrativa de Aura, de Carlos Fuentes (2001).

\section{Visión}

La realidad presentada por Fuentes en el inicio de la novela - realidad esa aparentemente llena de sentido, pues no subvierte las leyes y normas de la sociedad - puede ser entendida como "la superficie sólida e inmutable”, pero vulnerable a los efectos de las fisuras o rajaduras, que Alazraki (2001) apunta en su ensayo sobre lo neofantástico. Esa realidad que lo fantástico tradicional de Tzvetan Todorov (1975) asume desde una perspectiva verosímil es entendida como un antifaz usado para esconder una segunda realidad que puede ser vislumbrada a través de las pequeñas aberturas que lo neofantástico ha provocado en la superficie de la realidad normatizada. En Aura, esta segunda realidad puede ser representada por la antigua habitación de la calle de Donceles. Allí presente y pasado conviven no sólo en la arquitectura de la construcción de los edificios, sino en los personajes y acontecimientos que se chocan con la realidad que el personaje Felipe ha experimentado anteriormente.

La aparente duplicidad existencial de los personajes permite observar en la narrativa una confluencia de tiempos distintos en un mismo espacio dimensional, o sea, pasado, presente se confunden, al paso que el futuro, corrompido por la certidumbre, dialoga con el presente y pierde su principal característica: la sorpresa. 


\section{Intención}

Alazraki (2001) afirma que la intención de la narrativa neofantástica, diferentemente de lo fantástico, no es producir el miedo, sino la perplejidad o inquietud, a través de la presencia de lo insólito de las situaciones narradas. Su verdadero propósito es expresar, por medio de metáforas, vislumbres, entrevisiones o lo que Borges definió como siendo "intersticios de sinrazón" que "escapan al lenguaje de la comunicación, que no caben en las celdillas construidas por la razón, que van a contrapelo del sistema conceptual o científico con que nos manejamos a diario" (ALAZRAKI, 2001, p. 277).

Aura hace parte de un primer ciclo de obras de Fuentes denominado El mal del tiempo. La obra del escritor mexicano está, con frecuencia, asociada a un elemento temporal: sea en referencias al pasado histórico de su país o sea a un tiempo ligado a la "zona sagrada" de los mitos, como advierte Ramón Xirau (1997).

El elemento metafórico contenido en Aura puede representarse en la narrativa por la fuerte presencia del pasado, que de cierto modo aludiría al pasado histórico de México, y por la simbología del comportamiento de los personajes femeninos que remitirían a los ceremoniales de las civilizaciones precolombinas.

La presunta reencarnación de los personajes de Felipe y del general Llorente sugiere que el autor ha tocado en un tema polémico de forma intencional, ya que México es un país de mayoría católica. El tema de la reencarnación traería a la discusión la posibilidad de un tiempo cíclico para la existencia humana, lo que es rechazado por el pensamiento cristiano. De nuevo el pretérito, lo antiguo parece adquirir un tono alegórico en la novela de Fuentes. A partir de la introducción y representación del pasado en la trama el autor resucita o reencarna, sería más adecuado, hechos que remiten a los orígenes del pueblo mexicano. Todos esos temas están íntimamente ligados a la narrativa neofantástica.

\section{Modus operandi}

Para explicar este último trazo de lo neofantástico, Alazraki (2001) hace una comparación con la estructura del cuento fantástico tradicional: el discurso 
fantástico parte de una situación perfectamente natural para alcanzar lo sobrenatural. La evocación del miedo es la razón de ser del cuento fantástico, según apunta Todorov (1975). El relato neofantástico, afirma el autor, prescinde también de los bastidores y utilerías que contribuyen a la atmósfera o pathos necesaria para esa rajadura final. Sin embargo, desde las primeras frases del relato, el cuento neofantástico nos introduce al elemento fantástico: sin progresión gradual, sin utilería, sin pathos. Pero mientras el cuento fantástico se mueve en el plano de la literalidad, de los hechos históricos del argumento, el relato neofantástico alude a sentidos oblicuos o metafóricos o figurativos.

De ese punto de vista el propio personaje que da nombre a la obra de Fuentes, según algunas interpretaciones, puede ser apenas una proyección de la mente perturbada de la anciana Consuelo que viviría, en la novela, presa a sus propias reminiscencias:

Sabes, al cerrar de nuevo el folio, que por eso vive Aura en esta casa: para perpetuar la ilusión de juventud y belleza de la pobre anciana enloquecida. Aura, encerrada como un espejo, como un icono más de ese muro religioso, cuajado de milagros, corazones preservados, demonios y santos imaginados. Arrojas los papeles a un lado y desciendes, sospechando el único lugar donde Aura podrá estar en las mañanas: el lugar que le habrá asignado esta vieja avara (FUENTES, 2001, p. 35).

Otro trazo fundamental, como advierte Alazraki (2001), de ese modus operandi de la narrativa neofantástica puede ser observado ya en las primeras líneas: el uso del "tu” subvertiría la tradición realista en la literatura.

\section{LA APRECIACIÓN DEL TIEMPO Y ESPACIO EN AURA}

Ciertos ambientes y fechas parecen representar más que simples espacios y marcos temporales, dan la impresión de estar llenos de significados. Misteriosamente, parecen abrir puertas en el tiempo para permitir una comunicación real con el pasado, como que ofreciera la oportunidad de entender algo que necesitara ser explicado en el tiempo presente. El joven Felipe Montero uno de los personajes principales de Aura, novela del escritor mexicano Carlos Fuentes (2001), parece haber encontrado uno de esos "pasadizos" que se comunican con espacios y tiempos distintos de nuestra realidad. Seducido o 
hechizado por una ventajosa propuesta de empleo que ha leído en un anuncio periodístico, el joven historiador llega a una antigua habitación en el centro viejo de la capital mexicana. Es en este ambiente que se desarrolla la trama narrativa en Aura, más precisamente en la atmosfera de misterio que envuelve a la casa y sus habitantes.

En compañía del personaje y revisitando ambientes y eventos por él experimentados se buscará trazar aquí un panorama de cómo el autor ha construido esos elementos del discurso narrativo.

En Aura podemos distinguir dos espacios físicos distintos: el espacio exterior a la habitación, es decir, el mundo del cotidiano urbano, lleno de calles, autos y personas; y el espacio interno de la casa, escenario de la trama narrativa. Sin embargo, una otra referencia espacial no menos significativa es el contorno del antiguo edificio, o sea, los alrededores de la casa que también demandan algunas observaciones.

El primero comprende el espacio físico, en que se inicia la historia, está caracterizado por elementos concretos, personas, cosas, vías, objetos, lugares, etc., es por lo tanto un ambiente que dialoga con la realidad. El cafetín sucio en que se encuentra Felipe, en el inicio de la novela, y la calle de Donceles son las dos extremidades de ese escenario.

El modo como el autor identifica el espacio y construye, en su entorno, la narrativa, permite al lector atestiguar la secuencia de acciones que van a desarrollarse en la trama. El lector parece observar a Felipe leer el anuncio del periódico, caminar a la esquina, tomar el autobús y, en el día siguiente, repetir algunas de esas mismas acciones, para, entonces, decidir irse al viejo centro de la ciudad, al otro borde extremo del escenario: la calle de Donceles.

Aunque esa secuencia de acciones sea breve, los elementos que se relacionan con la vida urbana, la realidad, son significativos, pues este referencial explícito de realidad creado por el autor va a deconstruirse en el instante que Felipe llega a la calle de Donceles.

El desorden en los números que identifican los edificios, algunos de ellos simbólicos, el aspecto sombrío de los segundos pisos de los viejos palacios, poco iluminados, las gárgolas, las ventanas ensombrecidas por largas cortinas, crean una atmósfera de misterio que se instala en el seno de la normalidad antes descripta por el autor. Se puede inferir que el autor al elegir este ambiente antiguo como escenario de la trama, avecina en un mismo espacio pasado y presente.

El primer contacto físico de Felipe con la casa ya señala la presencia del insólito: al coger la manija de la puerta, en forma de cabeza de perro, el joven 
tiene la impresión de que el animal allí representado le sonríe. Este evento aparentemente sobrenatural, instala la incertidumbre en la narrativa y sugiere que al entrar en la habitación el personaje dejará el espacio de lo real para entrar en un mundo desconocido. La propia construcción narrativa reforza esa suposición:

La puerta cede al empuje levísimo, de tus dedos, y antes de entrar miras por última vez sobre tu hombro, frunces el ceño porque la larga fila detenida de camiones y autos gruñe, pita, suelta el humo insano de su prisa. Tratas, inútilmente de retener una sola imagen de ese mundo exterior indiferenciado (FUENTES, 2001, p. 6).

El segundo escenario en la novela comprende la residencia habitada por los otros dos personajes de la historia: la anciana Consuelo y su sobrina Aura. Es un ambiente viejo, húmedo y prácticamente sin luminosidad, con excepción del cuarto en que Felipe va a acomodarse que recibe a través del tragaluz la claridad externa. La obscuridad del ambiente se confunde con el comportamiento de las dos figuras femeninas de la casa y poco a poco, Felipe se ve involucrado por ese aire de taciturnidad, pasando a confundir realidad con imaginación. El olor de humedad, el antiguo mobiliario, las imágenes religiosas, la presencia de animales y el color verde de las plantas, aludido con frecuencia, por el autor en la narrativa, componen este escenario.

Zaguán, aberturas, aposentos, vernáculo, cocina, corredores... cada rincón de la casa surge en la novela de modo a no apenas componer el ambiente, sino constituirse en espacios que desempeñan funciones que exteriorizan el carácter y el comportamiento de los personajes. Las escenas que ocurren de forma simultánea en dos de los ambientes apuntados anteriormente - la recámara de la anciana y la cocina - en que se procesan escenas aparentemente propias de rituales, sugieren que espacios y personajes están conectados, que se comunican a través de la atmósfera de horror instalada en la construcción narrativa.

El alrededor de la vivienda constituye un espacio singular en la novela. Especie de sitio fronterizo entre el mundo externo y parte interna de la casa, este espacio es caracterizado por la presencia de lo insólito. El juego entre razón e ilusión, trazo característico de lo fantástico tradicional, es engendrado por el autor provocando, en el personaje y en el lector, la vacilación, apuntada por Todorov (1975): “Dudas, al caer sobre la butaca, si en realidad has visto eso; quizás sólo uniste esa imagen a los maullidos espantosos que persisten, disminuyen, al cabo terminan” (FUENTES, 2001, p. 22). 
El supuesto jardín, visto o imaginado por el personaje, es el punto clave de ese escenario. En ese ambiente fantasía y realidad se mezclan. Sensaciones físicas propias de los sentidos humanos, como oír (maullidos) y sentir (olor del pelambre incendiada de gatos) son experimentadas por el personaje y después puestas en duda, deconstruidas o hasta negadas en la propia narrativa. El autor se utiliza del dialogo entre Felipe y Consuelo para producir tal efecto, es decir, la ambigüedad:

- Está bien, señora. ¿Podría visitar el jardín? - ¿Cual jardín, señor Montero? - El que está detrás de mi cuarto. - En esta casa no hay jardín. Perdimos el jardín cuando construyeron alrededor de la casa. - Pensé que podría trabajar mejor al aire libre. - En esta casa solo hay ese patio oscuro por donde entró usted. Allí mi sobrina cultiva algunas plantas de sombra. Pero eso es todo. - Está bien, señora (FUENTES, 2001, p. 23).

Esas observaciones ligadas al espacio difieren, en cierta medida, de los cuentos fantásticos tradicionales. Por ejemplo, la descripción del espacio evanescente, cambiante, especie de pasadizo de intercomunicación temporal, provoca más perplejidad que propiamente el miedo típico de lo fantástico.

La instancia tiempo en Aura se presenta de manera muy peculiar, intrincada. Al dar inicio a la lectura de las primeras líneas de la novela podemos percibir que el autor utiliza la segunda persona para desarrollar la narrativa. La utilización del "tu" en el futuro para describir acciones que van a ocurrir al personaje Felipe, confiere a la novela un tono premonitorio. En la trama narrativa presente y futuro se mezclan en la voz del narrador. Como sabemos al final de la narrativa el personaje se reconocerá en la figura del marido de Consuelo, el general Llorente. El hecho de usar la segunda persona en un tiempo futuro sugiere que el propio Felipe sea ese "tu", es decir, él, en una especie de autoenfoque, es al mismo tiempo narrador y personaje. Suposiciones aparte tratemos de explorar (o hacer intentos) de forma más detenida la construcción temporal en Aura.

En la primera parte de la novela, además de las marcas de tiempo verbales aludidas anteriormente, se puede percibir que la novela obedece a un orden cronológico. En el primer escenario, el espacio urbano ya identificado aquí, la sucesión de hechos se da en un intervalo de días. El narrador anuncia de modo profético que Felipe vivirá el primer día (lo día en que se inicia la historia) de forma idéntica a los demás, y al día siguiente repetirá algunas acciones, cuando decidirá caminar hacia la calle de Doncelles: "Vivirás ese día, idéntico a los demás, y no volverás a recordarlo sino al día siguiente, cuando te sientes de 
nuevo en la mesa del cafetín, pidas el desayuno y abras el periódico" (FUENTES, 2001, p. 5, grifos nossos).

La mezcla entre el presente y el futuro aparece de forma explícita y sugiere que el narrador posee conocimiento y dominio totales de la historia que está contando. Al penetrar en la habitación el juego entre presente y futuro permanece en la narrativa, pero las marcas temporales ahora son reducidas al ritmo del reloj, al intervalo de minutos y horas: "Consultas tu reloj y recuerdas que Aura te ha citado en su recámara [...] Te acercas cautelosamente a la puerta de doña Consuelo y no escuchas un solo ruido. Consultas de nuevo tu reloj: apenas son las nueve" (FUENTES, 2001, p. 35).

La alternancia entre día y noche también marca el desenlace de las acciones: "Al despertar, buscas otra presencia en el cuarto y sabes que no es la de Aura la que te inquieta, sino la doble presencia de algo que fue engendrado la noche pasada" (FUENTES, 2001, p. 40).

La tarea para que ha sido contratado el historiador, escribir las memorias del general Llorente, le permite hacer contacto con un tiempo pasado. El autor a través de los escritos del general, introduce el pasado en la narrativa, como si quisiera dar explicación a los conflictos, las dudas, vividas por el personaje en el presente. Las informaciones ofrecidas por el pasado, y que llevan al personaje reconocerse en la persona del general Llorente, provocan en el protagonista un estado de alienación, de enajenación mental. El tiempo cronológico da lugar al tiempo psicológico, a partir de este punto el autor abandona el tiempo presente y pasa a usar el futuro en el desenlace de las acciones: “Tú ya no esperarás. Ya no consultarás tu reloj. Entrarás a la recámara. Recordarás que la vieja ha estado ausente todo el día y que la cera se habrá consumido. [...] Avanzarás en la oscuridad, hacia la cama. Repetirás: - Aura...” (FUENTES, 2001, p. 47-48).

Nuevamente esta instancia se acerca de lo neofantástico al presentar un modo peculiar de representación del tiempo distinto de la mayoría de los contos fantásticos. La sobreposición temporal, la mezcla entre presente/futuro, entre pasado/presente, la propia predicción del futuro se constituyen en trazos inequívocos de la narrativa neofantástica.

\section{CONCLUSIÓN}

El género fantástico ha sido el punto de partida para entender y calificar un nuevo tipo de literatura, surgida bajo la influencia de los movimientos van- 
guardistas europeos del inicio del siglo XX: la ficción neofantástica. El concepto de realidad íntimamente ligado a lo fantástico tradicional se ha modificado, a partir de la segunda mitad del siglo XX, principalmente, en Latinoamérica, bajo la narrativa de escritores como Jorge Luis Borges, Julio Cortázar, Carlos Fuentes, entre otros. Así, lo neofantástico, según Jaime Alazraki (1988, p. 178), promueve "esfuerzos orientados a un contacto más genuino, más real, con la realidad”. Apoyado en ese mismo autor, se hizo un análisis sucinto de cómo se presentan en la narrativa los trazos que caracterizan esa modalidad literaria. Se ha elegido, en esta tarea, la obra Aura, producida por el escritor mexicano Carlos Fuentes (2001), para investigar los elementos tiempo y espacio según la óptica de lo neofantástico.

\section{The neo fantastic in Aura, by Carlos Fuentes: spatial and temporal dimensions in the narrative construction}

\section{Abstract}

The present work tries to analyze the narrative over Aura, by Carlos Fuentes, from the perspective of the neo fantastic, according to the argentine critic Jaime Alazraki. The dimensions of time and space are prioritized as a characterization of elements of this literary modality. Initially, a brief panorama of the context of the emergence of the neo fantastic is drawn from the perspective of the critic Rámon Xara.

\section{Keywords}

Neo fantastic. Weather. Space.

\section{REFERENCIAS}

ALAZRAKI, J. Borges, entre la modernidad y la postmodernidad. Revista Hispánica Moderna, New York, n. 41, p. 175-179, dez. 1988. Disponible en: https://pt.scribd. com/document/238129454/Alaraki-Jaime-Borges-Entre-La-Modernidad-y-La-Postmodernidad-Revista-Hispanica-Moderna-41-1988-175-179-Best. Accedido el: 8 jan. 2021. 
ALAZRAKI, J. ¿Qué es lo neofantástico? In: ROAS, D. Teorías de lo fantástico. Madrid: Arco Libros, 2001.

FUENTES, C. Aura. 40. reimp. Ciudad de México: Ediciones Era, 2001.

ROAS, D. (org.). Teorías de lo fantástico. Madrid: Arco Libros, 2001.

TODOROV, T. Introdução à literatura fantástica. São Paulo: Perspectiva, 1975.

XIRAU, R. Crisis del realismo. In: MORENO, C. F. América Latina en su literatura. 4. ed. Ciudad de México: Siglo Veintiuno Editores, 1997. 